\title{
Flip sides of the same coin? A simple efficiency score versus energy bill savings information to drive consumers to choose more energy-efficient products
}

\author{
Anne Arquit Niederberger • Guy Champniss
}

Received: 6 December 2016 / Accepted: 22 May 2017 /Published online: 18 August 2017

(C) The Author(s) 2017. This article is an open access publication

\begin{abstract}
Together with our utility clients, Enervee is experimenting with behavioural intervention strategies to see which are most effective in nudging purchasing decisions toward more efficient products. This paper presents results on decision-making, preferences and online shopping behaviour obtained from a series of observational (utility-branded marketplace platform analytics) and experimental studies (randomized controlled trials). Within the trials, we tested potential direct and interaction effects of two distinct but related energy product attributes that improve market transparency: an energy score (a relative product model energy efficiency index) and energy savings (estimated energy bill dollar savings compared to a base model benchmark). The trials all show that the use of an energy score has a significant effect on consumer product choices, encouraging them to select more energy-efficient products, consistent with the observational data. These robust results make a strong case for leveraging heuristicsbased nudges to drive energy-efficient purchasing
\end{abstract}

\footnotetext{
A. Arquit Niederberger $\cdot$ G. Champniss

Enervee, 2100 Abbot Kinney Blvd Unit D, Venice, CA 90291, USA

A. Arquit Niederberger
e-mail: anne@enervee.com

G. Champniss $(\bowtie)$

Visiting Fellow, Cranfield School of Management, Cranfield University, College Road, Cranfield, Bedfordshire MK43 0AL, UK

e-mail: guy@enervee.com

e-mail: G.Champniss@cranfield.ac.uk
}

behaviour at scale. Responses to the energy bill savings information varied across the studies, offering insights about the influence of buying context and decision styles on consumer choice. The simple-to-process energy score appears to elicit a hot/impulsive decision style, whilst the cognitively more complex energy bill savings information prompts a reflective/cool decision style. Overall, the studies provide intriguing and robust insights to inform the continued development of costeffective and scalable interventions to drive more energy-efficient consumer product choices.

Keywords Behavioural intervention strategies . Consumer product energy efficiency $\cdot$ Decision attributes $\cdot$ Decision styles

\section{Introduction}

The product choices that consumers make when purchasing appliances, equipment and electronic gadgets that consume natural resources during their operational phase lock in consumption over their lifetime. Typical useful lifetimes for major domestic appliances range from 10 to 15 years, with shorter lifetimes for electronics and longer lifetimes for heating, ventilation and air conditioning (HVAC) equipment. Given the need to dramatically reduce greenhouse gas emissions in the immediate future, if we are to limit the average global temperature increase to between 1.5 and $2{ }^{\circ} \mathrm{C}$, the billions of one-time purchasing decisions being made by consumers annually matter. 
Televisions alone consume an astounding 7\% of national purchased electricity in the USA (EIA 2015) — only slightly less than water heating (9.2\%) or refrigeration $(7.5 \%$ ) - and TV and other consumer electronics' electricity demand is expected to grow further (NRDC 2015). Fortunately, the best commercially available consumer products and residential HVAC equipment offer tremendous scope to reduce energy requirements below business as usual. Our data show that the most efficient TVs offered on the US market use $40 \%$ less than the market weighted average for new TVs (Arquit Niederberger 2016a). Influencing 30\% of US product purchase decisions across four product categories (refrigerators, dishwashers, dryers, TVs) in a single year to super-efficient models with Enervee Scores ${ }^{1}$ of 90+ would save 15,100 GWh (see Fig. 1), more energy than needed to meet the annual residential electricity demand of Los Angeles and Sacramento combined.

With such clear opportunities for both energy and financial savings, why is it that many energy-efficient consumer products continue to suffer from very low uptake? Product efficiency incentive schemes have been dominated by financial incentives, delivered in the form of rebates (CEE 2015), presumably seeking to overcome perceived financial barriers or inattention to energy efficiency. Yet policymakers and regulators are increasingly encouraging market transformation approaches that tackle underlying market barriers directly, recognizing that untargeted financial rebate schemes are fraught with free ridership - and poor uptake amongst the low-income population (Cluett et al. 2016), where financial barriers would be expected to be most relevant-as well as low cost-effectiveness, especially for product categories without significant incremental costs.

Underinvestment in energy efficiency is often attributed to imperfect information and, increasingly, rational inattention (a form of 'bounded rationality'; Simon 1955). The idea behind rational inattention is that when information is costly to acquire, decision-makers sometimes choose to act upon incomplete information, rather than incurring the cost to become perfectly informed (Sallee 2014). Estimating the value of future energy costs that could be avoided by purchasing an efficient appliance is beyond the abilities or motivation of most consumers and requires data that are not readily available.

\footnotetext{
${ }^{1}$ The Enervee Score is a daily updated index (on a zero to 100 scale) of the relative energy efficiency of a given product model, relative to all new products of the same size or capacity currently offered for sale.
}

Consumers are more likely to be rationally inattentive if perceived effort costs are high, the range of unknown energy costs is low and in cases where the product that is their first choice is very different than other model options (e.g. a TV with $4 \mathrm{k}$ resolution vs. a standard resolution TV). Attempting to overcome rational inattention by incentivizing consumers to pay attention is not welfare improving, since increased attention involves the real opportunity cost of taking the time to consider efficiency implications, which might be larger than the potential energy bill savings. Thus, eliminating barriers to information acquisition and processing may be a more promising approach than prodding consumers with price incentives (Sallee 2014).

This has been attempted with mandatory and voluntary government labels, but the literature suggests that labels have not been a silver bullet (Newell and Siikamäki 2013; Davis and Metcalf 2014) and may come with unintended consequences, such as dampening manufacturers' and consumers' motivation to offer and purchase products that exceed the qualification requirement (Houde 2014), or leading consumers to pay more for labelled products than justified by their associated energy savings (Newell and Siikamäki 2013; Houde 2014). A problem with existing labels that include energy information is that they are not accurate for individual consumers, as they are based on averages and usage assumptions that cannot be personalized (Newell and Siikamäki 2013). The consumption of HVAC equipment, for example, varies geographically, as do electricity tariffs (currently averaging $\$ 0.25 / \mathrm{kWh}$ for residential customers in Alaska and Hawaii, compared with under $\$ 0.11 / \mathrm{kWh}$ in 11 states $^{2}$ ), and households exhibit wide variations in activity levels.

Together with client utilities across the USA and Europe, Enervee is addressing imperfect information and rational inattention consequences, through consumer marketplaces that can support targeted incentives, ${ }^{3}$ as needed, as well as other interventions, and which function across all product categories. Enervee (www. enervee.com) is a software-as-a-service ('SaaS') company, featuring utility-branded product efficiency marketplaces that allow consumers to review and select

\footnotetext{
$\overline{2}$ Data for August 2016, https://www.eia.gov/electricity/monthly/epm table_grapher.cfm?t=epmt_5_6_a

${ }^{3}$ Given heterogeneity in investment inefficiencies and other factors across the population and geographies, targeted policies have the potential to generate larger welfare gains than general subsidies or mandates (Allcott and Greenstone 2012).
} 


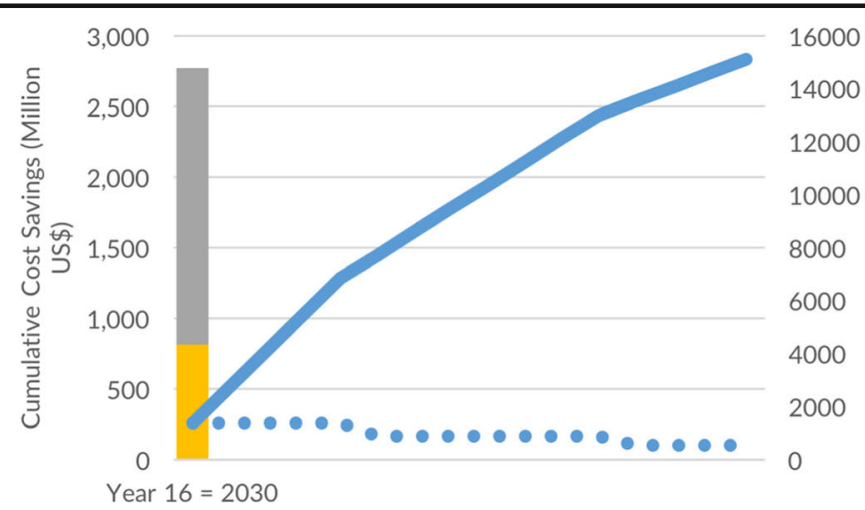

16000

14000

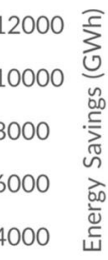

2000
Energy Bill Savings

Avoided Social Cost of Carbon

Cumulative Energy Savings

-. Annual Savings Shift 30\% 2016 Sales

Fig. 1 Cumulative impact of positive influence on US sales for four product categories in a single year

more efficient products via specific data points that relate both to the specific product and the specific use case for the consumer, and, in the USA at least, to proceed to more efficiently claim rebates on those new purchases, where offered by their utility.

Utilities that license the platform typically do not choose to sell products direct to consumer; rather, they leverage the marketplace to facilitate energy-smart purchase decisions and transactions between their customers and established and trusted market intermediaries, such as retailers. As such, Enervee Marketplace is an intermediate (or initial) step for consumers, acting as a decision aid, with a focus on energy performance attributes of all products. Prices and retailers are updated daily (or at sale times, intra-daily), to ensure consumers are given the most up-to-date information regarding purchase price and availability. To date (April 2017), Enervee is working with 11 utilities in North America and Europe (France and the UK), servicing approximately 47 million households.

Utility case study research from the USA suggests that consumers in Northern California generally wish to consider energy in their shopping decisions, but have difficulty obtaining the information they need (Binley et al. 2016), as illustrated by the information gaps presented in Fig. 2.

To understand the influence of imperfect information, Enervee is committed to a research agenda to study the effects of both information disclosure and the presentation style or framing of that information, on product choice and purchase decisions. This agenda brings together a number of extant research themes focused on eliciting prosocial behaviours from consumers. On the one hand, defaults (e.g. Johnson et al. 2002) as choice-architectdesigned reference points have been shown to be effective in motivating consumers to make choices that improve both their and social welfare (Beshears et al. 2007), particularly where consumers perceive the 'effort tax' (Sunstein 2013) to override the default as too high. At the same time, however, defaults have to be credible and salient (Sunstein 2013); otherwise, they fail to provide a suitably accurate or relevant feedback mechanism to affect consumer choice change (Karlin et al. 2015).

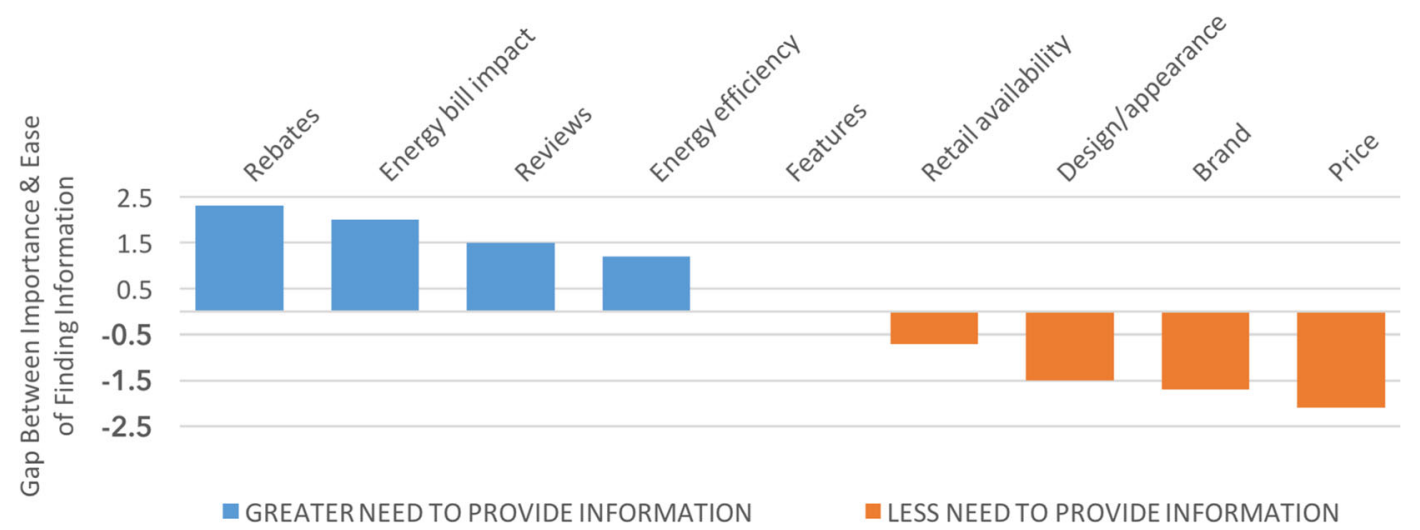

Fig. 2 Product decision-making information gaps (data source: Binley et al. (2016)) 
Energy savings from a more efficient specific appliance purchase, shown to the consumer in a dollar amount and predicated on salient default values (e.g. hours or use, years of ownership), may represent a good use of defaults to provide consumers with salient feedback regarding a modified, more prosocial, choice. Indeed, defaults within the energy consumption content have been proven effective (Sunstein and Reisch 2014).

Alternatively, behaviours may also be modified without the typical requirement for an aligned predecisional attitude. This can be achieved through nudges (Thaler and Sunstein 2008), which focus on eliciting the target behaviour. Nudges can leverage mental shortcuts, or heuristics (e.g. Kahneman et al. 1991) that are used by individuals in specific decision contexts, characterized by peripheral (Petty and Cacioppo 1986), impulsive (Strack et al. 2006) or 'hot' (Peters et al. 2006) choice styles, or they can exploit inherent biases (Tversky and Kahneman 1974) that individuals struggle to override, e.g. present bias (Tversky and Kahneman 1974) or mental accounting effects (Thaler 1985). As such, whilst information is undoubtedly important in guiding consumers toward more efficient choices-which includes timely and salient feedback regarding those choices based on relevant and credible defaults, for example - there are also opportunities to secure efficient purchases through what could be considered less 'cognition-heavy methods', leveraging heuristics or biases. More specifically, a gaze heuristic could be used to encourage consumers to 'simply' look for the highest value on a scale (e.g. an energy scale with a $0-100$ range).

This agenda draws on both observational data from consumer marketplaces live in the field, as well as randomized controlled trials, using bespoke versions of marketplaces under test conditions. Both approaches deliver the benefit of being based on observed choices, revealed preferences and behaviours in the marketplace, rather than the more typical self-stated responses that remain highly susceptible, in this specific context, to social desirability bias (Fisher 1993).

\section{Study overview}

This paper reports results from four distinct but linked studies, relying on a combination of observational data (study 1) and data collected from a series of randomized controlled trials (studies 2-4). Study 1 analyses observational data from live utility consumer marketplaces to ascertain consumer willingness to handle two key energy efficiency data points which are unique to Enervee's Marketplace - a relative product energy efficiency ranking (energy score) and associated energy bill savings (energy savings) - as a precursor to using these data points to steer their purchasing decisions. Study 2 then tests the influence of these specific energy efficiency factors on revealed consumer preferences via a randomized controlled trial. Study 3 repeats these tests, but with a specific consumer sample to reveal product preferences amongst financially constrained consumers. Finally, study 4 tests whether buying context - a rushed purchase due to a broken appliance versus a planned purchase as part of a general remodelling programinfluences both consumer preferences for energyefficient products and the effectiveness of the energy score and energy savings to steer consumers toward more efficient purchases.

\section{Study 1 -online sort behaviour}

\section{Methods}

The online behaviour of visitors to six live utility marketplaces in the $\mathrm{USA}^{4}$ (located in CA, CT, OR, WA) was observed. These product efficiency marketplaces provide shoppers with daily updated information on energy-using consumer products, including major domestic appliances, electronics, HVAC equipment and LED replacement bulbs. In addition to the functionality that contemporary shoppers have come to expect from shopping comparison sites (e.g. best retail price, product photos and specifications, where to buy online and instore locally), the marketplaces address the key information gaps highlighted in Fig. 2:

- Utility rebates are fully integrated into each marketplace, and customers can apply online

- Personalized energy bill savings are provided, taking into account the average energy tariffs for each visitor (based on their location); users can further

\footnotetext{
${ }^{4}$ The marketplaces can be accessed under the following URLs: energizect.enervee.com; ladwp.enervee.com.; marketplace.pge.com; marketplace.sdge.com; and smartrewards.snopud.com.
} 
customize to take into account their own usage levels, as well as the time period over which they would like to consider the bill impacts

- Aggregated user reviews on a five-star scale for each product model are provided, and the original reviews can be consulted

- The relative energy efficiency of each product model is conveyed through a zero to 100 energy score (with 100 being the most efficient model at a given size/capacity)

We analysed Google Analytics event data for the 2month period from mid-March through mid-May 2016, specifically the actions that users took whilst on product category pages. The product pages analysed were clothes dryers, clothes washers, refrigerators, LED replacement bulbs, televisions, gas water heaters, electric water heaters and pool pumps. Some of the most common actions were loading more results, clicking on an individual product model to pull up further details and filtering the overall list of products to hone in on products that meet shoppers' needs (e.g. brand, price range, size range). Some users also chose to sort the product lists, and this is the analysis for which results are presented below.

Results

Figure 3 summarizes the sort actions aggregated across all six marketplaces for eight product categories. It should be noted that each utility features a different set of product categories. Whereas all product categories are sortable by energy attributes - both energy score and energy bill savings - as well as product model, size/capacity and price, utilities do not offer rebates on all categories. ${ }^{5}$

Across all product categories, marketplace visitors sorted more frequently by energy attributes than they did by retail price, in line with previous results for Pacific Gas \& Electric's Marketplace alone (Binley et al. 2016). The energy score was the most frequently used.

\footnotetext{
${ }^{5}$ At the time of this analysis, LADWP's Marketplace only included three rebated product categories (refrigerators, LED replacement bulbs and televisions), while PG\&E and SDG\&E included all eight categories, roughly half with rebates.
}

Study 1 discussion

These results lend support to the argument that an energy score has the potential to act as a heuristic for energy efficiency, in line with the findings of Newell and Siikamaki (2013). The argument is far less clear, however, on whether stated energy bill savings may offer a similar route to energy-efficient purchasing.

In order to isolate and test the direct and interaction effects of these two energy attributes on product selection, we designed a randomized control trial, manipulating the presence of these two attributes. The design, operationalization and results of this second study are detailed subsequently.

\section{Study 2-field experiment}

Hypotheses

The second study was designed and run to isolate specific effects on willingness to purchase, driven by two key pieces of information presented within the consumer marketplaces: the relative energy efficiency ranking (the 'energy score', presented as a 0-100 score) and the associated energy cost savings ('energy savings', presented in dollars).

Study 2 tested two hypotheses that are informed by both literature and the observational data obtained from study 1. Firstly, recognizing that consumers interact frequently with the energy score ranking for individual products (from the observational data) and that the ranking of $0-100$ is intuitive, easy to understand and interpret (Oppenheimer 2008), it is proposed that providing consumers with the relative energy efficiency of products on this scale (energy score) will lead to preferences for the more efficient products. Consequently,

\section{H1: Providing consumers with a 0-100 energy efficiency score for individual product models will have a positive and direct influence on consumers expressing a preference for more efficient products.}

Second, providing consumers with a positive dollar consequence of energy efficiency, in the form of energy bill savings, should clarify and make salient the personal financial benefits of an energy-efficient choice, and as such be a compelling argument (Newell and Siikamäki 2013). However, it is also recognized that other 
Enervee Score $\square$ Energy Bill Savings $\square$ Rebate $\square$ Size/Capacity $\square$ Model $\square$ Price

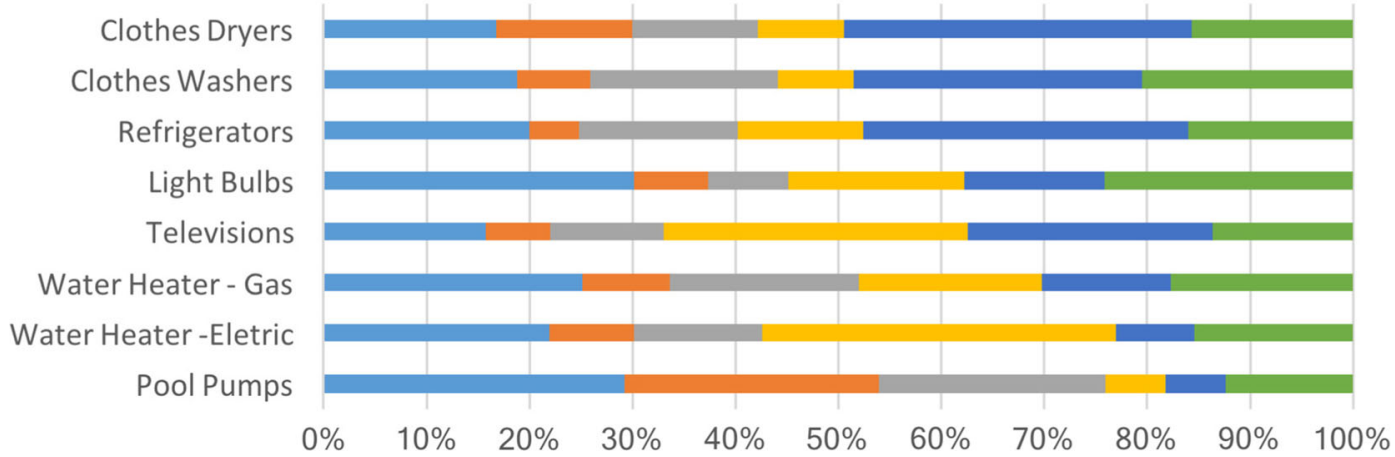

Fig. 3 Share of sort actions by product category and attribute (study 1)

psychological factors, such as inattention (Sallee 2014) and disproportionate individual discount rates (Hausman 1979), or the lack of personalization in projected energy savings (Davis and Metcalf 2014), may counter this influence. Nonetheless, it is proposed that, on balance, making the consumer benefit concrete and salient (through a specific dollar amount) will influence purchase preference, through alleviating rational inattention. This leads to our second hypothesis:

H2: Providing consumers with the projected financial savings from individual products, compared to a baseline product, will have a positive and direct influence on consumers expressing a preference for more efficient products.

A randomized controlled trial was established with four conditions created for respondents. This represented a $2 \times 2$, between subjects factorial design. The trial was run using a limited version of marketplace (one product category and a limited selection of models), with the four conditions as follows: score and savings (condition 1), score and no savings (condition 2), no score and savings (condition 3 ), and no score, no savings (condition 4). To clarify, a $2 \times 2$ design was chosen in order to also test for any interaction effect between the two manipulations.

Cover story, manipulations and sample

Respondents were invited to visit what they were led to believe was a prototype consumer shopping site, whereby consumers could research potential appliance products. The appliance in this instance was a frontloading washing machine, and they were presented with a choice of nine models (in line with the standard initial search results presented to users of live utility marketplaces). Respondents were requested to imagine they were in the market for a new washing machine purchase and were invited to review and explore the site. The manipulated test sites mimicked the marketplace sites in that respondents could see a search result page (list of washing machines), with key information next to each machine (see Fig. 4a) and could then explore any machine in more detail via the individual product model profile page (see Fig. 4b). The initial sort order of the search results was random (not determined by underlying energy efficiency) and was consistent across all four conditions. Respondents were able to move between search results and specific product profiles as often as they wanted. Before reviewing and exploring products, respondents were prepared to express their top three product choices, based on their experience on the site. They were informed that once they had made their first, second and third choices, they could proceed to express those choices.

Where the energy-efficient variables (energy score and energy savings) were removed from the user experience on the site for the respective conditions, 'filler' variables were inserted to maintain overall site experience and stimulus consistency. The filler variables were spin speed and whether the machine was stackable or not. Both attributes were already included in the summary details of the product within all four conditions, ensuring respondents were not receiving new information in these instances. 
a

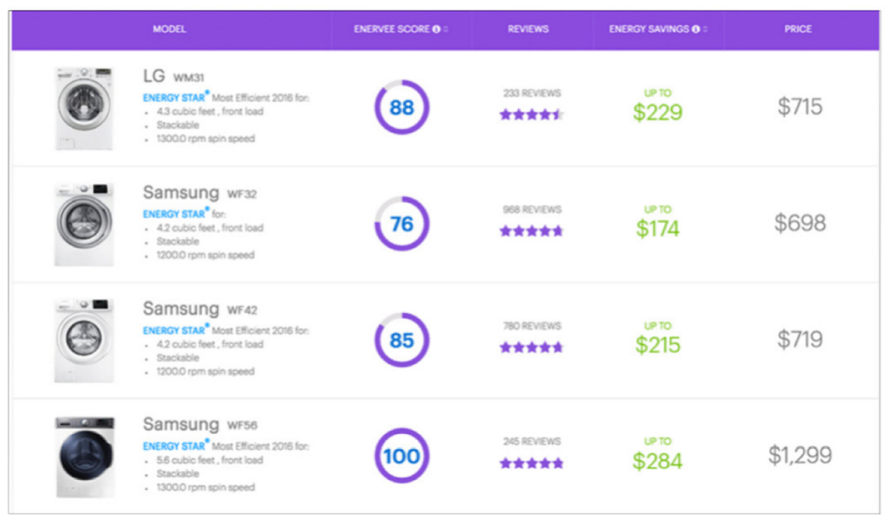

b

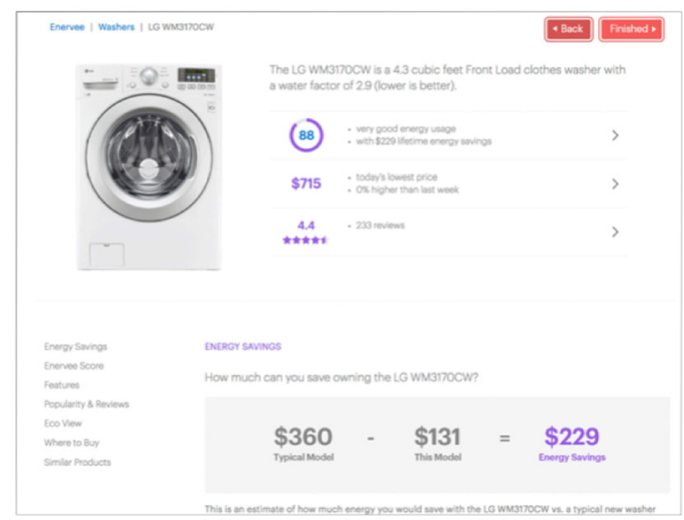

Fig. 4 a, b Search results and product profile pages for study 2 (RCT)

Two hundred respondents were recruited via an established academic research panel provider and were allocated at random across each condition until a cell sample of 50 was reached for each condition. Respondents were pre-screened for residency in the USA to bolster face and ecological validity of the study.

\section{Measures}

Respondents chose their top three washer models from the nine options provided. These choices represent the dependent variable for the study. The responses were measured through respondents allocating a ' $1,2,3$ ' position to their top three chosen products. Once the top three choices were recorded, perceptions of the marketplace's positioning (pro-energy saving) were measured (via a single Likert-style item). Finally, respondents were also measured for pro-environmental attitudes and disposition, via an established four-item scale (Schuhwerk and Lefkoff-Hagius 1995).

Results

\section{Direct effects}

To reiterate, respondents were asked to select their top three choices from a range of nine washing machines, with respondents exposed to conditions that presented either the energy score, the energy savings, both items, or neither item (as the control). Considering the $2 \times 2$ factorial design, analysis was conducted via ANCOVA.

Providing consumers with the energy score for products (the relative energy efficiency on a scale of $0-100$ ) has a significant and positive effect on energy-efficient product selection $(F=9.425, p<.01)$, with consumers presented with the energy score making a more energy-efficient first choice than those without the score $\left(M_{\text {EnergyScore } 1}=89.5, S D=8.43\right.$ vs. $\left.M_{\text {NoEnergyScore1 }}=85.5, S D=7.54\right)$. When looking at the average efficiency of the selected products across the three choices made, once again, the energy score effect is significant, with respondents exposed to the energy score making more efficient choices overall $\left(F=9.878, p<.01 ; M_{\text {EnergyScore 123 }}=87.3, S D=3.91\right.$ vs. $\left.M_{\text {NoEnergyScore } 123}=85.3, S D=3.96\right)$. As such, $\mathrm{H} 1$ is supported.

No direct effect is found for providing the energy savings information, either at the first choice level $(F=.22, p>.1)$ or at the combined three choice level $(F=.754, p>.1)$. Consequently, $\mathrm{H} 2$ is not supported.

\section{Interaction effects}

No significant interaction effect is found, either at the first choice level $(F=.193, p>.1)$ or the combined three choice level $(F=.307, p>.1)$. Whilst not finding support for $\mathrm{H} 2$, this result is nonetheless of interest and is discussed subsequently.

Controls and further measures

\section{Positioning of marketplace}

There is no significant direct effect of the energy score influencing consumer perception of the positioning of the marketplace $(F=1.821, p>.1)$, although the energy savings effect was significant $(F=15.08, p<.01)$, with those in the energy savings condition perceiving the site 
as more pro-energy efficiency $\left(M_{\text {EnergysSavings }}=6.14\right.$, $S D=.96$ vs. $\left.M_{\text {NoEnergySavings }}=5.32, S D=1.26\right)$. There was no significant interaction effect on perception of site positioning $(F=1.739, p>.1)$.

\section{Pro-environmental attitudes}

Finally, variations in pro-environmental attitudes and predisposition were not significant across the four conditions (item $1, F=.041, p>.1$; item $2, F=.000, p>.1$; item $3, F=.275, p>.1$; item $4, F=.138, p>.1$ ), lending support to the argument that significant effects recorded across the conditions are a product of the information manipulations (energy score and energy savings), and not in-sample biases.

\section{Study 2 discussion}

The results from study 2 support and build on the findings from study 1 , namely that the energy score is influential in delivering more energy-efficient choices - both the first choice and the average choice (across three selections). Moreover, whilst study 2 finds no support for our second hypothesis (H2), i.e. that energy savings make energy-efficient choices concrete for consumers, we tentatively propose it lends support to the argument that unless savings amounts are perceived as personalized, they fail to encourage energy-efficient behaviour due to a lack of relevancy or credibility.

Beyond the energy score and energy bill savings influences, the results of study 2 also reveal or confirm two other observations with important policy implications:

- Despite the fact that the energy score leads to more efficient product choices, consumers do not perceive the associated pro-energy efficiency positioning of the platform. That is to say, the energy score may be operating at a more subtle level, or indeed with the energy score not directly associated with a proenvironmental or energy-saving motive. This raises interesting questions regarding the oft-assumed need to overtly educate consumers in issues of energy efficiency. It is also worth mentioning that the pro-energy efficiency positioning was perceived within the energy savings cells. This further questions the value of such information and could indicate some form of environmental 'reactance'
(Brehm 1966), i.e. a behavioural pushback against the environmental message, which can occur when such a message is perceived by the recipient of being too strong, biased or overbearing, resulting in the individual re-exercising their control-in this case to select products that are not energy efficient.

- No significantly distinct pro-environmental attitudes were detected, lending support to the arguments that the trial controlled for any underlying environmental bias and exerted an effect at a subconscious level.

\section{Study 3 - field experiment}

Hypotheses

Whilst securing an effect from the energy score is both interesting and encouraging, especially considering no presence of pro-environmental attitudes amongst the respondents, study 3 focused on replicating the effect albeit with a different respondent sample. More specifically, study 3 focused on low-income respondents in order to better understand the potential for the energy score and energy savings information to influence purchasing preferences amongst this potentially difficultto-engage and particularly vulnerable group of consumers (e.g. Heffner and Campbell 2011; Hernández and Bird 2010).

Recognizing the intuitive and easy-to-process nature of the energy score, it is argued that financially constrained consumers will be similarly influenced by the energy score in terms of revealing more efficient preferences, since the higher score signals higher energy efficiency, which in turn leads to long-term financial savings. This leads to our third hypothesis:

H3: Providing low-income consumers with a 0 100 energy efficiency score for individual product models will have a positive and direct influence on consumers expressing a preference for more efficient products.

Moreover, low-income consumers may fixate or focus on communications referencing financial sums and figures (Mani et al. 2013), with the reference of money and savings alerting or priming their awareness of belonging to a financially constrained consumer group (Champniss et al. 2016). Consequently, it is 
argued that low-income respondents will use the energy savings figures presented to move their preferences toward more efficient models. This leads to our fourth hypothesis, namely

H4: Providing low-income consumers with the projected financial savings from individual products, compared to a baseline product, will have a positive and direct influence on consumers expressing a preference for more efficient products.

Cover story, manipulations, sample and measures

The cover story, manipulations and measures within study 3 were all identical to those presented in study 2 .

The sample for study 3 was taken from an established online academic panel provider and were pre-screened using the platform's own socio-economic filter, whereby panel members had previously ranked themselves on income, importance and social status. This was measured via a scale that ran from 0 to 10 , with 10 being the highest income, importance and social status. Respondents with scores of 3 or less were put forward for study 3. Again, 50 respondents were allocated at random to each condition within the study.

Results

Providing low-income consumers with the energy score for products (the relative energy efficiency on a scale of $0-100)$ has a significant and positive effect on energyefficient product selection $(F=19.145, p=0)$, with consumers presented with the energy score making a more energy-efficient first choice than those without the score $\left(M_{\text {Energyscore } 1}=89.32, S D=8.1 \mathrm{vs}\right.$. $\left.M_{\text {NoEnergyScore1 }}=84.49, S D=7.61\right)$. When looking at the average efficiency of the selected products across the three choices made, once again, the energy score effect is significant, with respondents exposed to the energy score making more efficient choices overall $\left(F=19.548, p=0 ; M_{\text {EnergyScore } 123}=86.89, S D=3.6\right.$ vs. $\left.M_{\text {NoEnergyScore } 123}=84.59, S D=3.58\right)$. As such, H3 is supported.

Regarding energy savings information, providing low-income consumers with this information has a partially significant effect with respect to their first choice $(F=3.29, p=.07)$ with consumers presented with the energy score making a more energy-efficient choice
$\left(M_{\text {Energysaving } 1}=87.91 S D=7.81 \mathrm{vs}\right.$. $\left.M_{\text {NoEnergySaving1 }}=85.91, S D=7.91\right)$. When looking at the average efficiency of the choices made, the energy score has a significant effect $(F=4.13, p<.05)$, with low-income consumers preferring more efficient models $\left(M_{\text {Energysaving123 }}=86.28 S D=3.61 \mathrm{vs}\right.$. $M_{\text {NoEnergySaving123 }}=85.22, S D=3.75$ ). As such, $\mathrm{H} 4$ is tentatively supported.

\section{Interaction effects}

No significant interaction effect is found, either at the first choice level $(F=.895, p>.1)$ or the combined three choice level $(F=.346, p>.1)$.

Study 3 discussion

We find tentative support for our hypothesis that providing low-income consumers with energy savings information leads to more efficient product preferences. In addition, the energy score demonstrates a significant effect amongst this group also. This lends overall support to the argument that with low-income consumers, both factors could be instrumental in driving more efficient purchases. However, once again with no interaction effect observed, support continues to build for the argument that these two factors trigger distinct effects in terms of influencing consumer preference. Our tentative suggestion at this stage is that the energy score may elicit a hot/impulsive decision style due to it being simple to process and the natural desire to 'score' as highly as possible. Conversely, the energy savings information prompts a more reflective/cool decision style, due to the added cognitive request.

\section{Study 4 -field experiment}

Hypotheses

Frequently within energy efficiency buying research, much weight is given to broad demographics and psychographics in terms of a segmentation to predict the tendency to purchase (e.g. Fankel and Tai 2013; Finisterra do Paco et al. 2009). Recognizing that decision-making style, e.g. hot versus cold (Peters et al. 2006), reflective versus impulsive (Strack et al. 2006) or peripheral versus central (Petty and Cacioppo 1986), could vary from product purchase to product 
purchase, we considered it important to tentatively test the capabilities of the energy score and energy savings factors in different buying contexts. In the final study, then, we chose to add a manipulation to the cover story, priming some respondents to consider their buying context for the purposes of the study as one where their washing machine has just broken down and needs replacing quickly (a 'distressed' purchase) or one where they were remodelling their home and had the opportunity to replace the washing machine in this process (a 'planned' purchase).

We argue that within a distressed purchase environment, the locus of attention of the consumer will be on replacing the appliance as quickly as possible, and cognitive load will be high due to the perceived pressure of needing to replace the product. In this instance, we propose a focus on energy efficiency in the form of the energy score will be lower, due to increased cognitive load in ego depletion, resulting in a more impulsive decision more oriented toward instant gratification or goal meeting (e.g. Shiv and Fedorikhin 1999), than in the case of a planned purchase, since the latter affords the consumer more time to consider their options, with energy efficiency a relevant criterion. This leads to our fifth hypothesis:

H5: Consumers within a distressed purchase context will make less energy-efficient choices than consumers within a planned purchase context.

That said, considering the simplicity, or 'fluency' (Reber et al. 1998) of the energy score, we anticipate that consumers will buy more efficient products when the energy score is present. In the distressed purchase condition, we propose this will occur since the score represents a useful aid to a fast or 'hot' decision-making style. In the planned purchase condition, the score will be an easy-to-process piece of information that can be easily laid onto the various other aspects of the decision. This leads then to our sixth hypothesis:

H6: Providing consumers across both buying conditions with a 0-100 energy efficiency score for individual product models will have a positive and direct influence on those consumers expressing a preference for more efficient products.

Finally, considering respondents now have a more contextualized buying scenario (by virtue of being told either it is a distressed purchase or a planned purchase), we propose the energy savings will become more relevant and influential in influencing preferences. In the same way, the energy savings were salient for lowincome respondents in study 3 , so we propose their salience will increase now for all respondents, by virtue of a more ecologically valid buying scenario. This leads to our final hypothesis:

H7: Providing consumers across both buying conditions with the projected financial savings from individual products, compared to a baseline product, will have a positive and direct influence on those consumers expressing a preference for more efficient products.

Cover story, manipulations, sample and measures

Apart from adding the manipulation to the cover story, all other aspects of the story, the manipulations and the measures within study 4 remained the same as in the previous two studies. With respect to sample, respondents were again drawn from the same academic panel provider. Fifty respondents were allocated at random to each of the four conditions.

\section{Results}

Consumers placed in the distressed purchase condition made a first choice preference that was significantly different than the first choice of those consumers in the planned purchase condition $(F=5.05, p<.05)$, with those in the planned purchase condition revealing a preference for a more efficient product $\left(M_{\text {Planned1 }}=87.6\right.$, $S D=7.69$ vs. $M_{\text {Distressed1 }}=86.1, S D=7.14$ ). When looking at the top three choices, the same pattern emerges $(F=6.01, p<.05)$, with those in the planned buying condition revealing preferences for more efficient products $\left(M_{\text {Planned123 }}=86.14, S D=3.64\right.$ vs. $\left.M_{\text {Distressed123 }}=85.46, S D=3.46\right)$. As such, H5 is supported.

With respect to the first choice, there is a direct effect of providing the energy score to consumers $(F=30.2$, $p=0$ ), with a significant increase in energy-efficient preferences when the energy score is present $\left(M_{\text {Energyscore } 1}=88.9 S D=7.33 \mathrm{vs}\right.$. $\left.M_{\text {NoEnergyScore } 1}=84.84, S D=7.5\right)$. Regarding the top 3 choices, a significant effect is seen $(F=29.84, p=0)$, 
with those seeing the energy score revealing preferences for more efficient products $\left(M_{\text {EnergyScore123 }}=86.78\right.$, $S D=3.86$ vs. $M_{\text {NoEnergyScore } 123}=84.85, S D=3.23$ ). As such, H6 is supported.

Regarding energy savings information, when it comes to the first choice, there is a significant effect $(F=7.29, p<.01)$, with consumers seeing the energy savings information revealing preferences for more efficient products ( $M_{\text {EnergySaving1 }}=87.88, S D=7.66$ vs. $\left.M_{\text {NoEnergySaving1 }}=85.87, S D=7.18\right)$. Regarding the top 3 choices, the effect is also significant $(F=5.862, p<.05)$ with consumers consistently choosing more efficient products when shown the energy savings information $\left(M_{\text {EnergySaving123 }}=86.23, S D=3.57 \mathrm{vs}\right.$. $\left.M_{\text {NoEnergySaving123 }}=85.37, S D=3.53\right)$. As such, $\mathrm{H} 7$ is supported.

\section{Interaction effects}

No significant interaction effect is found between energy score, energy savings or buying context, at the first choice level $(F=2.54, p>.1)$, but a significant interaction effect is seen at combined three choice level $(F=3.906, p<.05)$. This three-way interaction effect is shown graphically in Fig. 5.

\section{Study 4 discussion}

In this final study, we have found support for consumers seemingly discounting energy efficiency criteria when in a distressed purchasing condition, when compared to a more measured, planned buying condition. Considering these are two likely and distinct buying contexts, these results lend support to the argument that traditional demographic and psychographic segmentation bases are, at the very least, not alone in predicting preferences and are, at worst, inappropriate for such predictions, considering their lack of consideration for such granular and potentially fleeting influences. However, in both manipulated buying conditions, we continue to find support for the energy score leading to more efficient choices. This is extremely encouraging, as this result is supported in the initial observational data study and maintains across all three subsequent experimental studies. As is discussed more fully momentarily, this simple (for the consumer, at least!) measure appears to be robust in driving more energy-efficient choices. We also see support in this final study for the effectiveness of the energy savings information. Whilst absent from study 1 , we propose the effect is seen here as the enriched buying context leads to higher face validity for the respondents, in turn meaning the factor becomes salient to the individual and their decision-making style. Again, this lends support to the argument that a second lever is available to influence consumers.

Finally, there is also a three-way interaction effect in this final study. This supports the argument that the relationship between the energy score and the energy savings is influenced by the buying context. Whilst not formally hypothesized, it can be argued that this is to be expected since it is likely the decisionmaking styles are very different across these two buying conditions. More specifically, in the planned buying context, energy efficiency may well be a valid criterion for consideration, and the energy score provides an easy and intuitive guide to maximizing this attribute. As such, when energy savings are also added alongside the energy score, there is no significant step-up in efficiency, since the energy score has already delivered that shift in decision. Conversely, in the distressed buying condition, we posit that the energy score may be too abstract and distant from the more tangible financial criteria most likely more salient under such conditions. However, when energy savings - in concrete dollars - are presented alongside the energy score, there is a significant increase in preferences for energy-efficient alternatives. This, we argue, is due to the energy savings contextualizing the energy score in a less abstract way that is meaningful to distressed buyers, namely showing a dollar saving impact. With the energy score now quantified for these shoppers, the score then becomes a useful and concrete proxy to then make even more efficient choices, as this fluently signals greater dollar savings for the distressed buyer.

\section{Overall discussion and conclusions}

This paper reports results from a series of observational and experimental studies, designed and run in concert, to explore and then test the effectiveness of two distinct, but related, pieces of energy efficiency information (energy score and energy savings). Study 1 focused on granular observational data relating to consumer behaviour within an online consumer product marketplace. Specifically, it was found that marketplace visitors sorted more frequently by these two energy attributes 
a

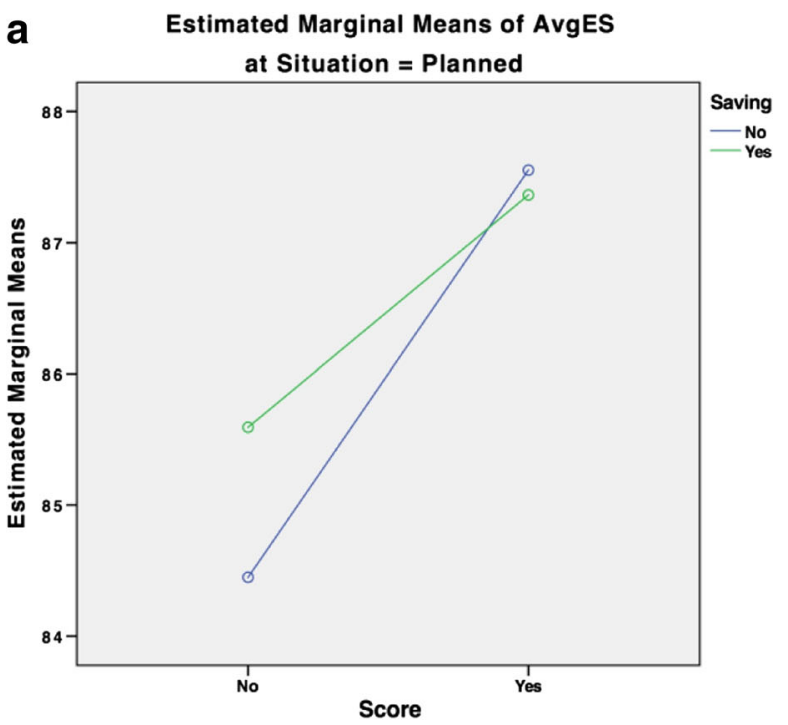

b

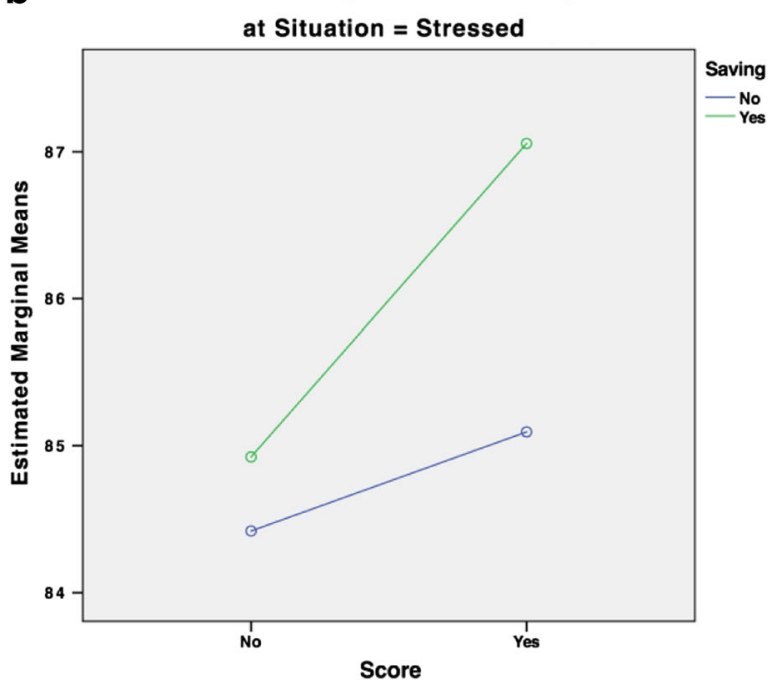

Fig. 5 a, b Three-way interaction effect between energy score, energy savings and buying context (a planned, b distressed)

than they did by retail price and that the energy score was the most frequently used.

Studies 2 through 4 then created a series of RCT experiments to further test and isolate any effects of these pieces of information, as well as to identify any shifts in attitudinal response toward the platform, or toward a pro-environmental position more broadly. Building on the finding that marketplace visitors rely more frequently on the energy score than on other product attributes to sort when researching products, the results from study 2 showed that providing consumers with the energy score also has a significant and positive effect on the energy efficiency of products selected. The effect of the energy score was then replicated for low-income respondents in study 3 and was also seen in study 4 , regardless of buying context.

In parallel, our research considered the effect of providing energy bill savings information. Study 2 did not support the hypothesis that providing consumers with energy bill savings data affects product selection. At first glance, this appears disappointing. However, it is important to remember that within the experimental design, this data point was presented as a generic saving (which did not account for individual washing machine usage rates, local energy and water tariffs or the fuel used by each household for water heating). This was clearly a limitation in the study design but, at the same time, points to supporting the need to further test the potential of personalized savings. In addition, we gained further insights on the salience of energy bill savings from the subsequent studies.

Unlike the general population in study 2, study 3 showed that low-income respondents select more efficient washer models when they are provided with the estimated bill savings, as well as with the product energy scores. Financial sums and figures might generally be more salient for shoppers struggling to make ends meet. In our discussion of the study 4 results, we posit that the salience of the bill savings information may have been increased for the wider population, just by providing an enriched buying context can lead to higher face validity for the respondents.

The fact that there was no interaction effect between the two energy attributes in study 3 suggests that they function in different ways to elicit the desired response. Our tentative suggestion that the simple-to-process energy score elicits a hot/impulsive decision style, whilst the cognitively more complex energy bill savings information prompts a reflective/cool decision style, was supported by study 4 , which explored the effect of purchasing context. Consumers faced with the need to quickly replace a broken appliance (distressed purchase) selected significantly less efficient washer models than those in the planned purchase condition, who had plenty of time to research their choices. However, the energy score continued to be effective across both buying conditions. Moreover, the three-way interaction effect points to buying context influencing decision-making 
style. Whilst this feels intuitively correct, study 4 offers early empirical support for this view.

The effectiveness of a relative energy efficiency score in encouraging energy-efficient consumer buying behaviour and preference was supported by all four studies. These robust results make a strong case for leveraging heuristics-based nudges to drive energy-efficient purchasing behaviour at scale. Interestingly, where heuristics-based interventions run the continual risk of failing once novelty disappears, the elegance of an energy score is that it need only influence a one-time purchase decision, which 'bakes in' relative energy savings over the lifetime of that product.

Harnessing big data to integrate a relative energy efficiency score throughout the modern consumer product shopping journey has great potential to eliminate market inefficiencies and thereby transform markets with minimal intervention, no reduction in choice and a sustained energy gain. It is an approach that aligns well with ambitious energy efficiency goals and strategies, as well as the emerging role of utilities as facilitators of transactions between customers and distributed energy resource providers. Our findings suggest new opportunities to empower households, including low- and moderate-income households, to shop resource smart.

We have reported on the integration of a relative energy efficiency score in a growing number of consumer-facing, utility-branded product efficiency marketplaces (currently serving over 47 million households in the USA and Europe), and the score is also deployed by retailers, manufacturers and publishers, enhancing our ability to reach shoppers when and where they make their purchase decisions. Overall, the studies provide intriguing and robust insights to inform the continued development of costeffective and scalable interventions to drive more energyefficient consumer product choices. It is the clear view of the authors that the potential of an intuitive energy score to affect such choices - without financial incentives or the need for explicit education and argument development-is both sizeable and realizable.

\section{Limitations and directions for further research}

The authors recognize several limitations of these studies and identify multiple directions for further research. Firstly, these studies focused on one specific product category; more product categories should be tested. Second, and as already noted, the energy bill savings presented were static and generic. Further studies would seek to identify effects from variable and customizable versions, which are already enabled on 'live' utility marketplaces. Related to this limitation, it is recognized that energy savings benefits can be presented in a range of formats, which may make effective use of established psychological accounting theory (cf. Thaler 1985). That is to say, presenting consumers with an energy saving may not be as effective as presenting the consumer with a total cost of ownership, for example. Whilst using the same underlying data structure, the marketplace could look to make this information more salient through alternative frames. To this end, Enervee's nonexperimental Marketplace does indeed give consumers the choice to toggle between alternative views (savings versus total costs), although it is recognized that consumers on the platform currently have to, in effect, self-select the most salient presentation of the information. Further studies to better understand how different defaults influence resultant choices would further contribute to the potential effectiveness of the platform as an intervention.

Third, it is also recognized that the platform - under these experimental conditions - did not recognize that many such purchasing decisions within the household are made, or at least influenced, by a multitude of actors (Mum, Dad, children, etc.), or are extremely contingent on timing and context. Further and more elaborate studies should be undertaken to better understand the contextand identity-driven influences (cf. Champniss et al. 2015) in such purchases. Related to this point, it may be argued that the effectiveness of the platform to influence within 'hot' or impulsive decision contexts is questionable. This is for the simple reason that if your washing machine breaks down and you need to replace it in a hurry, you may not use an online platform for this service. Whilst the authors recognize this point, they tentatively argue that online retailers have made considerable strides in the last year alone to make the online purchase of major appliances both efficient and trustworthy. According to the NPD Group, online sales of major home appliances in the USA increased by $38 \%$ in 2016 over $2015,{ }^{6}$ which the authors would propose is an indication of growing consumer convenience and trust in online purchasing for these categories and, by association, a broadening of valid contexts within which to buy online, which can include rushed or 'hot' purchases. Anecdotally, this is further supported by

\footnotetext{
${ }^{6} \mathrm{https}: / / w w w . n p d . c o m / w p s / p o r t a l / n p d / u s / n e w s / p r e s s-r e l e a s e s / 2017$ /online-major-home-appliance-sales-are-on-the-rise-summer-andwinter-holiday-promotions-are-driving-sales-growth-reports-npd/
} 
the impressive customer experience offered now by retailers such as Amazon and AO.com (the UK), who offer to deliver and install major appliances within $24 \mathrm{~h}$, with noquibble and hassle-free return options. These developments are contributing to a rash of physical appliance store closures. Consequently, the authors would argue that such a buying environment is increasingly relevant and viable for less planned and more rushed purchases.

Fourth, it is recognized that as a result of consumers not being able to actually purchase products on the 'marketplace', there may be moderating effects when the consumer then clicks through to the retailer site, i.e. intentions to buy energy-efficient products may be disrupted in that final step. The authors certainly acknowledge this as a limitation, but attempts are made within the non-experimental version of the platform, through minimizing the contact time and friction that a consumer may experience when leaving the marketplace site and landing on the retailer site. This includes linking directly to the product page of the retailer, whereupon the consumer can immediately place the product in their basket and proceed to checkout. In addition, Enervee is exploring placing the 'buy' button from the retailer within the marketplace platform, which would further reduce the friction and potentially mitigate for any possible retailer mediation effect. Moreover, the authors are confident that intentions per se should be maintained, due to the selection of the energy-efficient product on the marketplace representing a pre-commitment (Ariely and Wertenbroch 2002) to buy energy-efficient, and a desire to avoid subsequent cognitive dissonance (Festinger 1954) that may occur through deviating from that more efficient decision. This assumes of course that there are no perceived barriers to enacting that intention of course (Theory of Planned Behaviour (TPB); Ajzen 1991), and the authors recognize this caveat. Affiliate purchase data across categories confirm that actual marketplace-influenced purchases are double-digit more efficient (and less costly) than the average product available.

Finally, it is acknowledged that such behavioural, market-based interventions undertaken by utilities are not a panacea; rather, they complement other strategies, such as mandatory performance standards that have been effective in eliminating the worst products from the market. Nonetheless, the energy score — and the data behind it - can support the efforts of other actors to transform markets (Arquit Niederberger et al. 2015). The energy score offers a dynamic benchmark for the best commercially available technology to stimulate continual product innovation by manufacturers (Binley et al. 2016). Since the score is granular and dynamic, manufacturers can showcase efficiency innovation and derive a marketing and brand advantage from offering products that are 'better than good' (i.e. that sit toward the top end of the highest existing energy label for consumers). Similarly, the score can enable retailers to promote efficient products in-store and online. And daily consumer product market data can help policymakers analyse efficiency trends, ratchet up the stringency of standards in step with the pace of innovation, ensure compliance with product standards (Binley et al. 2016) and devise strategies to stimulate innovation at the cutting edge of efficiency. In concert, leading utilities, regulators, governments, retailers and manufacturers are leveraging consumer product market data and using targeted, closed-loop marketing to usher in a new era of energy-smart shopping that is poised to play a critical role in achieving residential energy efficiency targets (Arquit Niederberger 2016b; Arquit Niederberger et al. 2015).

Acknowledgments Thanks to our Enervee colleagues, Vivian $\mathrm{Li}$ for the data and statistical analysis support, and Ricky Weeks and Toby Welch for helping design and implement the experimental platform.

\section{Compliance with ethical standards}

Conflict of interest The authors declare that they have no conflict of interest.

Open Access This article is distributed under the terms of the Creative Commons Attribution 4.0 International License (http:// creativecommons.org/licenses/by/4.0/), which permits unrestricted use, distribution, and reproduction in any medium, provided you give appropriate credit to the original author(s) and the source, provide a link to the Creative Commons license, and indicate if changes were made.

\section{References}

Ajzen, I. (1991). The theory of planned behavior. Organizational Behavior and Human Decision Processes, 50(2), 179-211.

Allcott, H., \& Greenstone, M. (2012). Is there an energy efficiency gap? Journal of Economic Perspectives, 26(1), 3-28.

Ariely, D., \& Wertenbroch, K. (2002). Procrastination, deadlines and performance: self-control by precommitment. Psychological Science, 13(3), 219-224.

Arquit Niederberger, A. (2016a) Seeing the bigger picture? How to buy your dream TV and make sure it's energy efficient, Discover Enervee ${ }^{\circledR}$ - Nudging the World to Shop Resource-Efficient (blog), Medium, March 23, 2016, http://nrv.ee/1NBUp9H. 
Arquit Niederberger, A. (2016b) CEC highlights benefits of utility marketplaces - key market transformation effort in statewide action plan, Discover Enervee ${ }^{\circledR}$ - Nudging the World to Shop Resource-Efficient (blog), Medium, December 15, 2016, https://blog.enervee.com/cec-highlights-benefits-of-utilitymarketplaces-767362c53775

Arquit Niederberger, A., Katzman, A., Li, V. and Kurwig, M. (2015) Innovation in residential energy efficiency programs - the power of big data and closed-loop marketing. In: Proceedings of the 8th International Conference on Energy Efficiency in Domestic Appliances and Lighting EEDAL'15, 506-514.

Beshears, J., Choi, J., Laibson, D. and Madrian, B. (2007) The importance of default options for retirement savings outcomes: evidence from the United States. NBER Working Paper No. 12009.

Binley, K., Arquit Niederberger, A., Champniss, G. and Katzman, A. (2016) Insights from PG\&E's Marketplace initiative on influencing purchasing decisions, In: Proceedings of the 2016 ACEEE Summer Study on Energy Efficiency in Buildings, 6-1 to 6-13.

Brehm, J. W. (1966). A theory of psychological reactance. New York: Academic Press.

CEE (2015) State of the efficiency program industry: budgets, expenditures, and impacts, Consortium for Energy Efficiency, 2015.

Champniss, G., Wilson, H., \& Macdonald, E. (2015). Why your customers' social identities matter. Harvard Business Review, 93(1/2), 88-96.

Champniss, G., Wilson, H., Macdonald, E., \& Dimitriu, R. (2016). No I won't, but yes we will: driving sustainability donations through social identity effects. Technological Forecasting and Social Change, 111, 317-326.

Cluett, R., Amann, J., and Ou, S. (2016) Building better energy efficiency programs for low-income households, ACEEE Report Number A1601, March 2016.

Davis, L. and Metcalf, G. (2014) Does better information lead to better choices? Evidence from energy-efficiency labels, NBER Working Paper No. w20720, November 2014, http://ssrn.com/abstract=2532301.

EIA (2015) Annual energy outlook 2015, U.S. Energy Information Administration, Washington DC, 2015.

Fankel, D. and Tai, H (2013) Giving US energy efficiency a jolt. McKinsey \& Co. http://www.mckinsey. com/industries/electric-power-and-natural-gas/ourinsights/giving-us-energy-efficiency-a-jolt

Festinger, L. (1954). A theory of social comparison processes. Human Relations, 7(2), 117-140.

Finisterra do Poco, A. M., Barata Raposo, M. L., \& Leal Filho, W. (2009). Identifying the green consumer: a segmentation study. Journal of Targeting, Measurement and Analysis for Marketing, 17(1), 17-25.

Fisher, R. J. (1993). Social desirability bias and the validity of indirect questioning. Journal of Consumer Research, 20, 303-315.

Hausman, J. A. (1979). Individual discount rates and the purchase and utilization of energy-using durables. The Bell Journal of Economics, 10(1), 33-54.

Heffner, G., \& Campbell, N. (2011). Evaluating the co-benefits of low-income energy-efficiency programmes. Dublin: IEA Workshop Report ht tps:// w w w i e . org/publications/freepublications/publication/low_income_ energy_efficiency.pdf.

Hernández, D., \& Bird, S. (2010). Energy burden and the need for integrated low income housing and energy policy. Poverty Public Policy, 2(4), 5-25.
Houde, S. (2014) How consumers respond to environmental certification and the value of energy information, NBER Working Paper No. w20019, March 2014, http://ssrn. com/abstract $=2421079$.

Johnson, E., Bellman, W., \& Lohse. (2002). Defaults, framing and privacy: why opting in-opting out. Marketing Letters, 13(1), 5-15.

Kahneman, D., Knetsch, J., \& Thaler, R. (1991). The endowment effect, loss aversion and status quo bias. Journal of Economic Perspectives, 5(1), 193-206.

Karlin, B., Zinger, J., \& Ford, R. (2015). The effects of feedback on energy conservation: a meta-analysis. Psychological Bulletin, 141(6), 1205-1227.

Mani, A., Mullainathan, S., Shafir, E., \& Zhao. (2013). Poverty impedes cognitive function. Science, 341(6149), 976-980.

Newell, Richard, and Juha Siikamäki (2013) Nudging energy efficiency behavior: the role of information labels, NBER Working Paper No. 19224, July 2013, http://www.nber. org/papers/w19224

NRDC (2015). Plug-in equipment efficiency: a key strategy to help achieve California's carbon reduction and clean energy goals. NRDC Issue Brief.

Oppenheimer, D. (2008). The secret life of fluency. Trends in Cognitive Sciences, 12(6), 237-241.

Peters, E., Vastfjall, D., Garling, T., \& Slovic, P. (2006). Affect and decision making: a 'hot' topic. Journal of Behavioral Decision Making, 19, 79-85.

Petty, R. E., \& Cacioppo, J. T. (1986). The elaboration likelihood model of persuasion. Advances in Experimental Social Psychology, 19, 123-205.

Reber, R., Winkielman, P., \& Schwarz, N. (1998). Effects of perceptual fluency on affective judgements. Psychological Science, 9, 45-48.

Sallee, J. (2014) Rational inattention and energy efficiency, University of Chicago, April 18, 2014, http://home. uchicago.edu/ sallee/inattention-jle-revision4.pdf.

Schuhwerk, M. E., \& Lefkoff-Hagius, R. (1995). Green or nongreen? Does type of appeal matter when advertising a green product? Journal of Advertising, 24(Summer), 45-54.

Shiv, B., \& Fedorikhin, A. (1999). Heart and mind in conflict: the interplay of affect and cognition in consumer decision making. Journal of Consumer Research, 26, 278-292.

Simon, H., \& A. (1955). A behavioral model of rational choice. The Quarterly Journal of Economics, 69(1), 99-118.

Strack, F., Werth, L., \& Deutsch, R. (2006). Reflective and impulsive determinants of consumer behavior. Journal of Consumer Psychology, 16(3), 205-216.

Sunstein, C. (2013). Deciding by default. University of Pennsylvania Law Review, 162(1).

Sunstein, C and Reish, L. (2014) Automatically green: behavioral economics and environmental protection. Harvard Environmental Law Review, 38 (1). Available at SSRN: SSRN: https://ssrn.com/abstract=2245657 or doi: 10.2139 /ssrn.2245657

Thaler, R. (1985). Mental accounting and consumer choice. Marketing Science, 4(3), 199-214.

Thaler, R., \& Sunstein, C. (2008). Nudge: improving decisions about health. Wealth and Happiness: Penguin.

Tversky, A., \& Kahneman, D. (1974). Judgement under uncertainty: heuristics and biases. Science, 185(4157), 1124-1131. 